\title{
Article \\ Effects of Verbal Encouragement and Performance Feedback on Physical Fitness in Young Adults
}

\author{
Martin Pacholek 1,2,*(D) and Erika Zemková ${ }^{3,4}$ (D) \\ 1 Health and Physical Education Department, Prince Sultan University, Riyadh 12435, Saudi Arabia \\ 2 Physical Education Department, College of General Studies, King Fahd University of Petroleum \& Minerals, \\ Dhahran 31261, Saudi Arabia \\ 3 Department of Biological and Medical Sciences, Faculty of Physical Education and Sports, Comenius \\ University in Bratislava, 81469 Bratislava, Slovakia; erika.zemkova@uniba.sk \\ 4 Faculty of Electrical Engineering and Information Technology, Sports Technology Institute, Slovak University \\ of Technology in Bratislava, 81219 Bratislava, Slovakia \\ * Correspondence: mpacholek@psu.edu.sa; Tel.: +966-(0)50-200-2099
}

check for updates

Citation: Pacholek, M.; Zemková, E. Effects of Verbal Encouragement and Performance Feedback on Physical

Fitness in Young Adults.

Sustainability 2022, 14, 1753. https:// doi.org/10.3390/su14031753

Academic Editors: Pedro Valdivia-Moral and Jose Luis Ubago

Received: 12 December 2021

Accepted: 29 January 2022

Published: 3 February 2022

Publisher's Note: MDPI stays neutral with regard to jurisdictional claims in published maps and institutional affiliations.

Copyright: () 2022 by the authors Licensee MDPI, Basel, Switzerland. This article is an open access article distributed under the terms and conditions of the Creative Commons Attribution (CC BY) license (https:// creativecommons.org/licenses/by/ $4.0 /)$.

\begin{abstract}
This study evaluates the effects on the performance of young adults undergoing physical fitness tests with external stimuli (verbal encouragement (VE), performance feedback (PF), goaloriented (GO) and a combination of external stimuli (CS)) and without external stimuli (WS). A group of 432 male students (age $19.1 \pm 2.1$ y, BMI $24.72 \pm 5.97$ ) was randomly selected for this study. They underwent a battery of fitness tests (bench press, 10 and $30 \mathrm{~m}$ sprints, and vertical jump) with and without external stimuli. The results showed greater improvements in mean power in bench press after PF compared to attempts WS (14.93 W, 3.43\%, $p=0.005)$, and after CS compared to WS (13.84 W, $3.18 \%, p=0.015)$. The time in the 10 and $30 \mathrm{~m}$ sprints decreased more profoundly after a combination of VE and GO compared to WS (0.021 s, 1.07\%, $p=0.000$ and $0.06 \mathrm{~s}, 1.23 \%, p=0.001$, respectively) and after CS compared to VE (0.015 s, $0.76 \%, p=0.004$ and $0.074 \mathrm{~s}, 1.52 \%, p=0.000$, respectively). Furthermore, the height of the jump improved more after VE than WS $(1.36 \mathrm{~cm}, 5.46 \%, p=0.000)$, after CS than WS $(1.94 \mathrm{~cm}, 7.79 \%, p=0.000)$, and after CS than VE stimulus $(0.58 \mathrm{~cm}, 2.21 \%, p=0.000)$. These findings indicate that external stimuli and their combination are more effective for achieving better results in physical fitness tests than without external stimuli. Therefore, practitioners should use verbal encouragement, performance feedback, goal-oriented stimuli, and their combinations during physical fitness testing in physical education classes in order to enable their students to achieve a better performance.
\end{abstract}

Keywords: physical education; fitness test; verbal encouragement; external stimuli; feedback

\section{Introduction}

Testing in physical education is used to obtain objective information about the physical fitness of students. It is not easy to motivate students to achieve their maximum effort during the process, and therefore, testing results could be influenced by many factors. The biggest role in this process is motivation, which is the reason for people's actions, desires, and needs [1]. Data from Egli et al. [2] showed that male students are more motivated by a need for power, competition and challenge. This climate could lead to increased enjoyment, ability, and effort of students to pursue their goals. Therefore, teachers should consider the types of communication and methods that students are motivated by and respond to positively [3].

One of the most important parts of motivation is the way we acquire certain skills, abilities and, therefore, confidence. This process is called motor learning, and it is usually defined as learning in which bodily movements play a major part. These movements are patterns of responses to recognized stimuli. The stimuli (perceived) may be visual, kinesthetic, auditory, or other sensory stimuli, or a combination of the stimuli of several 
senses. Learning takes place by conditioning a response to a stimulus [4]. Applied behavior analysis has begun to emphasize the importance of stimuli in controlling human behavior [5].

Positive feedback as a stimulus for intrinsic motivation could be effectively used in physical activity [6-8]. Badami et al. [9] distinguished two different types of feedback used while teaching and coaching: intrinsic feedback (response-produced feedback that is available to learners from their sensory system both during and as a consequence of the performance) and augmented feedback (information received from an external source that supplements the learners' own sensory information, intrinsic feedback). Both forms of feedback used together help students and athletes improve their performance [10]. Teachers can use feedback as a motivation tool, and it allows students to gather information about their performance or increase their motivation. Feedback may be delivered verbally, visually, or through written form $[11,12]$. The link between feedback received from PE teachers and students' perceived competence has also been confirmed in correlational studies. Koka and Hein [13] found that positively perceived teacher feedback predicted students' perceptions of competence and intrinsic motivation. The sports literature is equally replete with evidence of the important role of coaches' positive feedback on athletes' perceived competence and intrinsic motivation [14,15].

The other motivation stimulus that could be simply used during physical education classes is verbal encouragement (VE). It is very often used to motivate athletes to keep or increase effort during exercising or testing [16] and is recommended in several exercise testing guidelines [17-19] as positive stimuli for their performance. The positive effect of verbal encouragement was recorded during aerobic tests on athletes [20-28]. Significant changes of verbal encouragement were found in the change of direction [29], force production [30,31] and in maintaining central activation [32]. Further study confirmed these positive effects in strength performance regarding encouragement volume and word choice in strength tests [33]. On the other hand, recent studies [32,34] showed that verbal encouragement was insufficient for promoting strength or velocity-specific adaptation. An interesting study from Miller et al. [35] showed that a combination of stimuli could lead to better changes in strength parameters than by using just verbal encouragement.

Most studies have investigated the influence of verbal stimuli on athletes or physically active population with a small sample size or without a combination of stimuli, or on just one physical ability (e.g., endurance, strength). Therefore, the aim of this study is to investigate the effect of selected stimuli (verbal encouragement (VE), performance feedback $(\mathrm{PF})$, goal-oriented (GO), combinations of stimuli (CS) and without stimuli (WS)) on the results in physical fitness tests executed by university students. An intention is to point out the importance of using VE, PF, GO and CS by practitioners as a tool to motivate students to achieve better performance results during the fitness testing. It was hypothesized that external stimuli (VE, PF, GO) would have a greater effect on physical fitness performance than without external stimuli and, furthermore, that a combination of external stimuli would have a greater effect on students' physical fitness performance than using just one external stimulus (VE, PF, GO) or WS.

\section{Materials and Methods}

\subsection{Participants}

The study was a single-blind group, time-parallel experimental research with the dependent variable characterized by levels of physical fitness. The independent variables were the external stimuli that were used during testing. Participants of this research were 432 male students from KFUPM (age $19.1 \pm 2.1 \mathrm{y}$, BMI $24.72 \pm 5.97$ ) who fully completed all measuring activities. The medical history was taken to deselect unhealthy or injured students from the testing. Additional criteria for selection were their age, from 18 to 20 years, and registered members of the university. Sample size was calculated based on the number of students in the university $(10,000)$, and the confidence level was set to $95 \%$ and margin of error at 5. Cluster random sampling was applied during selection. Participants did not 
obtain information about the goals or hypotheses of the research until the end of the project. They were instructed to abstain from physical activity for two days, not eat for at least $3 \mathrm{~h}$ before testing, and try to execute each repetition with their maximal effort. The procedures followed were in accordance with the ethical standards on human experimentation stated in compliance with the 1964 Helsinki Declaration and its later amendments. The project was approved by the ethics committee of the Deanship of Scientific Research, King Fahd University of Petroleum and Minerals in Dhahran (SB181037).

\subsection{Questionnaires and Testing}

Data were obtained by demographic survey and measurements. The survey was applied before the measurement of different physical abilities. It was supposed to gather basic demographic information about students. All participants underwent a familiarization training during which the main purpose of each test and proper execution was explained and trial attempts were performed. Moreover, students performed the test exercises under easy conditions by warming up before testing to negate any learning effects and to increase the reliability of baseline measures. Emphasis was placed on the proper technique of execution of each exercise. They underwent four weeks of measurement of their physical abilities under different stimuli in counterbalancing conditions.

Three different fitness tests (FT) were chosen based on different physical abilities (acceleration and running speed and explosive strength of upper and lower body). These FT [36] were applied with and without external stimuli. All students had three attempts at each FT. The first attempt was always without the external stimuli and the next two were with external stimuli. The order of execution of FT with external stimuli was regularly changed (counterbalancing) during the testing. The measuring was always performed for the same length of time for each student in the morning hours. Five measurements were executed in three weeks. One ability was measured in two days with four days' rest between pre- and post-test measurements. Only the vertical jump test was executed in one day. All testing procedures were performed by the same person (principal investigator) to ensure the same volume and frequency of verbal encouragement or feedback during testing [37].

The following kinds of stimuli were applied:

- With external stimuli

- Verbal encouragement (VE-verbally motivate students;

- Performance feedback (PF-verbal feedback about their previous performance;

- Goal-oriented stimuli (GO)—reaching a certain goal-oriented aim;

- Combination of VE, PF and GO (CS).

- Without external stimuli-participants just performed particular tests without any external stimulus from examiner.

The fitness tests were performed in this order:

- Bench press-explosive strength of upper body;

- Sprints (10 and $30 \mathrm{~m})$-acceleration and speed;

- Vertical jump - explosive strength of lower body.

\subsection{Characteristics of Selected Tests and Their Justification of Selection}

\subsubsection{Bench Press}

The bench press is a common exercise for developing upper body strength. On the first day of measurement, students warmed up with ten push-ups and 4-6 repetitions with an empty barbell $(16-20 \mathrm{~kg})$. The instructor observed and corrected the proper execution of this exercise during warm up with each student and then the diagnostic series for assessing a one-repetition maximum (1RM) followed. Based on the results, 55-65\% from 1RM was calculated for each student. On the second day of testing, students used the same warming up as on the first day plus one repetition of their calculated weight and then the testing (with their 55-65\% from 1RM) of maximal power (W) was applied. Each student had 
three attempts with one repetition. The rest between each repetition was 20-30 s. Their task was to produce maximum acceleration during the concentric phase in each repetition of the different stimuli. The proper position of the body and chest press technique was visually controlled by the investigator. The subject lowered the barbell to the chest without touching during the transition from the eccentric to the concentric phase. Any repetitions that contacted the chest or failed to come within $\sim 0.05 \mathrm{~m}$ of the chest were disregarded and repeated after $1 \mathrm{~min}$ of rest. The FiTRO Dyne Premium was used to control the distance of the barbell movement. Participants' head, neck, back (thoracic area) and hips were lying on the bench, knees were bent in 90 degrees, and feet were on the floor approximately shoulder width apart. The hips, torso, and thighs were parallel with the ground [38]. Participants' grip width was set up during familiarization on the bench press exercise and was used for all repetitions. Students were required to keep the same grip width for the whole testing protocol.

The selected stimuli were:

- $\quad$ Students performed the exercise WS;

- $\quad$ PF was given to students about their maximal power from the previous repetition;

- Combination of PF and VE ("faster", "go");

Maximal power involved in the bench press exercises was monitored using the FiTRO Dyne Premium (FiTRONiC, Bratislava, SVK). Parameters obtained using this system in the bench press exercise were reported to be reliable by Jennings et al. [39] and Zemkova et al. [40]. This machine can measure the vertical speed and length of motion, particularly in strength exercises. This is thanks to a sensor, which is stretched with an ox of dumbbells. On the basis of weight and acceleration, the system can calculate force, power and position. The device was placed on the ground and connected to the barbell by a nylon cord. The cord was pulling while participants performed the exercise. The device consists of a sensor unit based on a precise encoder mechanically coupled to a reel. The reel rotates and measures velocity while the cord is pulling out. A personal computer connected via USB cable collected all signals from the device. The system operates on Newton's law of universal gravitation and motion. Instantaneous force while moving a barbell of a mass in the vertical direction is calculated as the sum of the gravitational force (mass multiplied by gravitational constant) and the acceleration force (mass multiplied by acceleration). The acceleration of the vertical motion (positive or negative) is obtained by derivation of vertical velocity, measured by a highly precise device mechanically coupled to the barbell. Power is calculated as the product of force and velocity and the actual position by the integration of velocity. Comprehensive software allows the collection, calculation, and online display of the basic biomechanical parameters involved in resistance exercises [41].

\subsubsection{The 10 and $30 \mathrm{~m}$ Sprint Tests}

The main aim of this test is to determine acceleration and speed. Both days of measurement started with warming up, which consisted of athletic running drills, dynamic stretching, and one full sprint of $15 \mathrm{~m}$. Then students sprinted the $30 \mathrm{~m}$ distance twice with the task of running as fast as possible with the different stimuli. The rest ratio between sprints was 1:15-1:20. Times of 10 and $30 \mathrm{~m}$ distances were measured.

The selected stimuli were:

- $\quad$ Students ran alone WS;

- Students ran alone with VE from the examiner ("faster, go, go, go") during the sprint.

Students made pairs (sprint with partner), where one of them was the hunter and the second the rabbit. The rabbit started about $3 \mathrm{~m}$ in front of the hunter. The task of the hunter was to finish the $30 \mathrm{~m}$ distance before the rabbit. The race started on the acceleration of the hunter. After the race, both students changed their roles. The hunter's time was measured with verbal encouragement from an examiner [37]

For assessing the speed of students, the FITRO Gates photocell device (FITRONIC, Bratislava, Slovakia) was used for the distances 10 and $30 \mathrm{~m}$. 


\subsubsection{Vertical Jump}

The vertical jump test measures explosive strength of the lower body. Students underwent a general warm up with jogging, squats and calf jumps and, at the end, performed four-practice attempts of vertical jump. The main test consisted of three vertical jumps with the hands placed on the hips and without bending their knees. The task was to jump as high as possible and stay on the mattress for the minimum time possible. The most powerful jump of the three was recorded. The rest period between the sets of three jumps was $40-60 \mathrm{~s}$.

The selected stimuli were:

- Vertical jump without any external stimuli;

- Vertical jump with a verbal encouragement from an examiner ("higher");

- Vertical jump with an aim to touch a ball (hanging above the student) with the forehead and with verbal encouragement from an examiner.

The criterion of level evaluation of jumping abilities was the height of the jump with an accuracy of $0.1 \mathrm{~cm}$. The height of the jump was measured with the FiTRO Jumper device (FITRONIC, Bratislava, Slovakia). The jumper consists of a special contact switch mattress connected by means of a special interface to a computer and uses the relationship $\mathrm{h}=(\mathrm{g} \times \mathrm{Tf} 2) / 8$ for measurement of jump height [42]. The system measures contact and flight times (with an accuracy of $1 \mathrm{~ms}$ ) during serial jumps and calculates basic biomechanical parameters. The reliability of the test has been proven to be sufficient enough to be applied to functional diagnostics of athletes [43]. The producer of FITRONIC s.r.o. guarantees accuracy and reliability of the device with certified simultaneous measurements. The device may be used for the assessment of explosiveness of the lower extremities and strength endurance of the lower extremities [44].

\subsection{Statistical Analyses}

Data analysis was performed by using the statistical program IBM SPSS Statistics 21 (IBM Corporation, Armonk, NY, USA). The mean and standard deviation (SD) were used for presenting the results of measurements. The Kolmogorov-Smirnov test for normality was used on all variables. Data showed a normal distribution. Repeated measures one-way ANOVA was employed with the Bonferroni post hoc test for finding differences between physical fitness variables after the test was performed without stimuli and with external stimuli. The level of significance was set at $p \leq 0.05$, and statistically significant differences were marked with a symbol $\left({ }^{*}\right)$.

\section{Results}

The results from the bench press (BP) exercise (Figure 1) showed that mean power improved by $14.93 \mathrm{~W}(3.43 \%, p=0.005)$ after PF stimulus (feedback about their power performance) compared to without stimulus (WS). Mean power also increased after a combination of stimuli-CS (performance feedback and verbal encouragement-VE) compared to WS by $13.84 \mathrm{~W}(3.18 \%, p=0.015)$. 


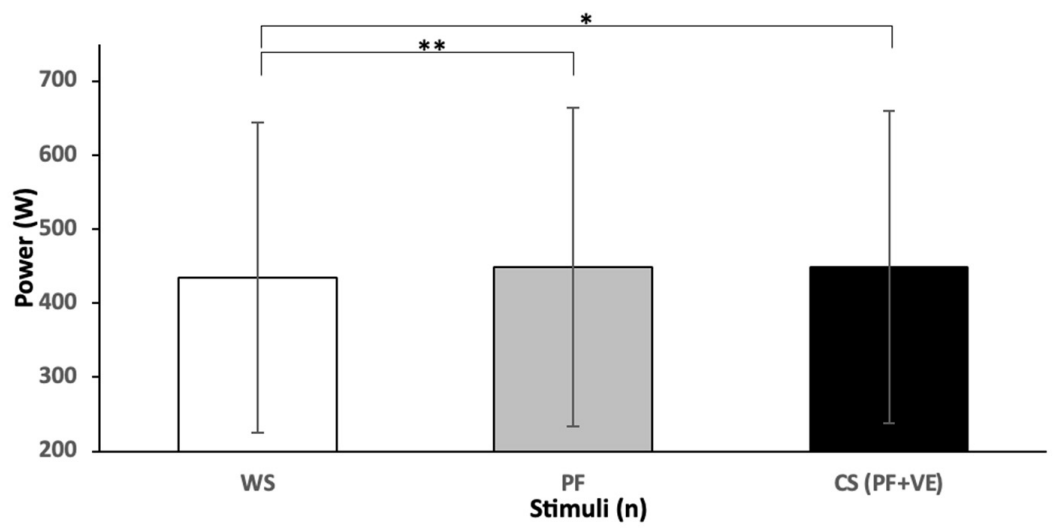

Figure 1. The mean power produced during bench press when applying different stimuli ${ }^{*} p \leq 0.05$, ** $p \leq 0.01)$.

In the $10 \mathrm{~m}$ sprint test (Figure 2), the time after CS $(\mathrm{GO}+\mathrm{VE})$ decreased compared to WS by about $0.021 \mathrm{~s}(1.07 \%, p=0.000)$ and the time decreased also after VE compared to WS by about $0.015 \mathrm{~s}(0.76 \%, p=0.004)$.

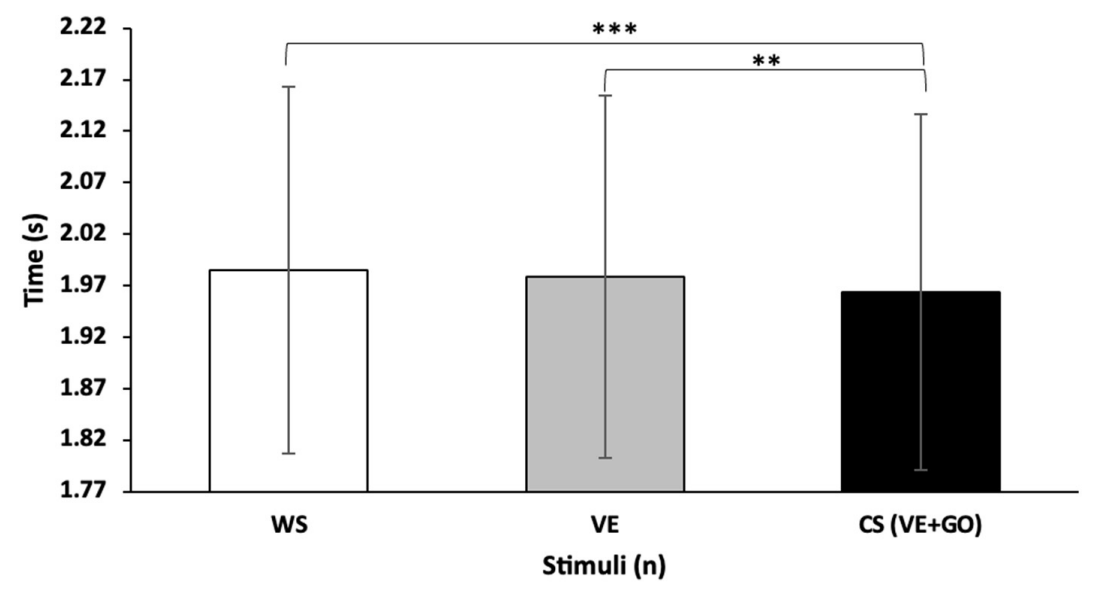

Figure 2. The time taken for the $10 \mathrm{~m}$ sprint with different stimuli $\left({ }^{* *} p \leq 0.01{ }^{* * *} p \leq 0.001\right)$.

The time for the $30 \mathrm{~m}$ sprint (Figure 3) decreased after CS compared to VE by $0.074 \mathrm{~s}$ $(1.52 \%, p=0.000)$, and the time also decreased after CS compared to WS by $0.06 \mathrm{~s}(1.23 \%$, $p=0.001)$.

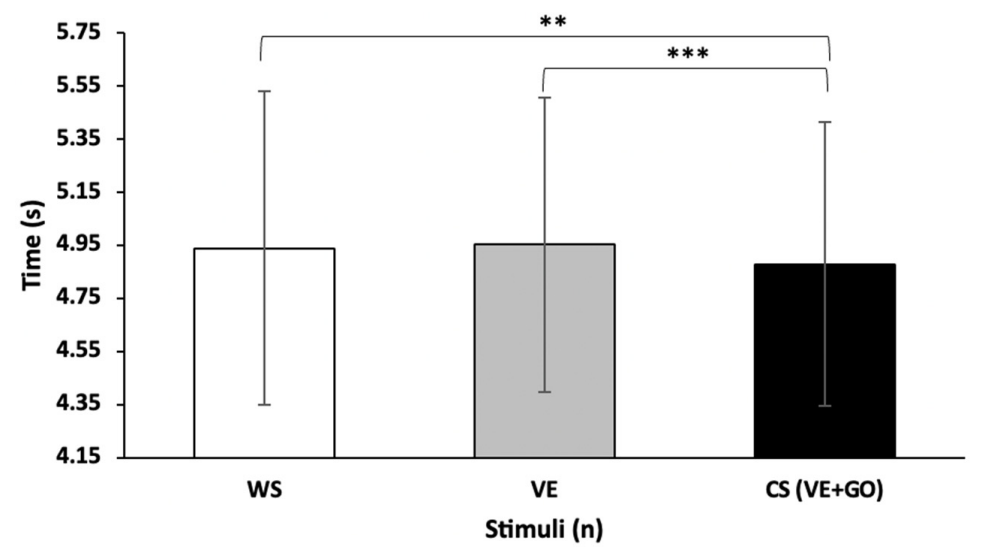

Figure 3. The mean time taken for the $30 \mathrm{~m}$ sprint with different stimuli $\left.{ }^{* *} p \leq 0.01,{ }^{* * *} p \leq 0.001\right)$.

The vertical jump test revealed (Figure 4) significant differences in height between all stimuli. CS (reach the subject + VE) was more effective compared to VE and WS. Students 
improved after VE to WS by $1.36 \mathrm{~cm}(5.46 \%, p=0.000)$. Improvements were also recorded after CS compared to WS by about $1.94 \mathrm{~cm}(7.79 \%, p=0.000)$ and after CS compared to VE $(0.58 \mathrm{~cm}, 2.21 \%, p=0.000)$.

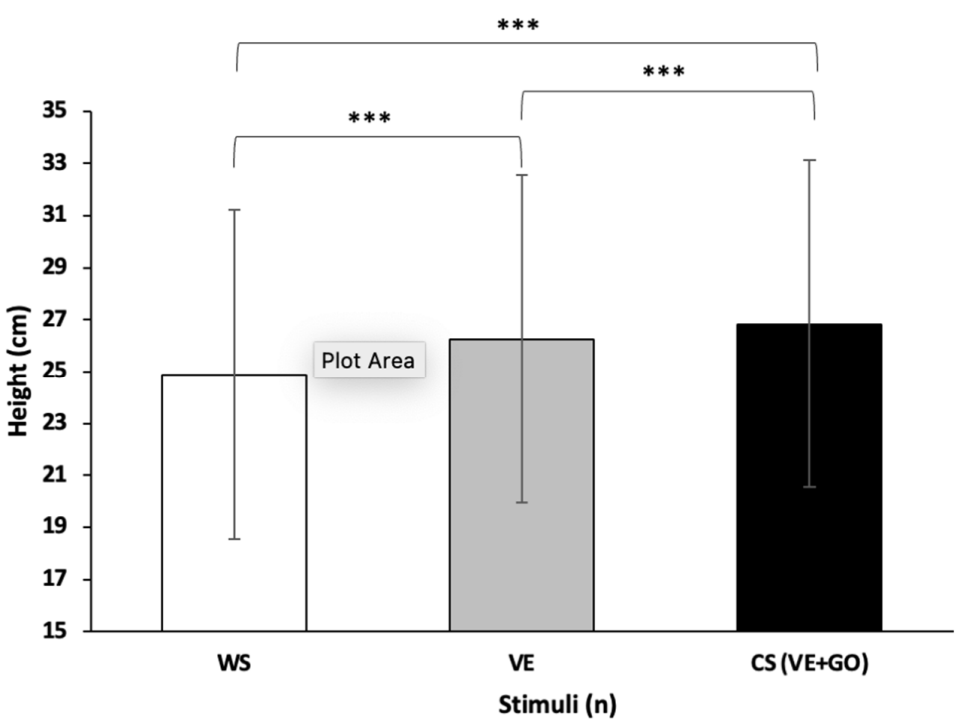

Figure 4. The vertical height of the jump at different stimuli (*** $p \leq 0.001)$.

\section{Discussion}

The results of the study support the hypothesis that external stimuli have a significant impact on the results from selected tests than without stimuli. This is recorded in all fitness tests. Only results from the 10 and $30 \mathrm{~m}$ sprint tests showed no statistically significant changes in performance between verbal encouragement and attempts without stimulus. The most significant changes were after applying a combination of verbal encouragement and goal stimulus. A combination of these external stimuli led to greater statistically significant changes than if just one external stimulus was used or without stimuli. This hypothesis was confirmed in acceleration and the speed test for 10 and $30 \mathrm{~m}$ and also in the vertical jump. In the bench press exercise, students improved significantly more after PF compared to WS, and no statistical changes were recorded between performance feedback and the combination of VE with PF. We can assume from these results that after applying a combination of stimuli and performance feedback, students perform better than after the application of verbal encouragement alone.

Statistically significantly smaller differences were recorded in the bench press exercise than in the sprint and jump tests, which could have happened because of the limited experience of students or because of the nature of this exercise. The other fitness tests in this study were closer to the basic movement activities (running, jumping), so for this reason the external stimuli could better enhance their performance. Small changes in strength testing were also observed in other studies $[28,45,46]$ after applying verbal encouragement to athletes. Their conclusion was that maximal strength performance might not be sensitive enough to external verbal stimulation. In the research on beginner athletes, Silva et al. [47] came up with results that they may show greater changes in strength, but it depends on their technical and motivational deficiencies. This confirms the research of Argus et al. [45], who stated that psychological interventions might have greater potential to affect performance in untrained or novice athletes. Lee et al. [32], in the recent study on sixty-five healthy males, came to the conclusion that verbal encouragement appears to be effective in maintaining central activation but is insufficient for promoting strength. In similar research, Rheese at al. [34] investigated the effects of verbally cued high "intended" movement velocity during knee extension training. The results demonstrated that verbal cueing did not alter the principle of velocity-specific adaptation. Miller et al. [35] examined changes between more stimuli in maximal isometric strength and found that knowing the 
results and combination of stimuli (knowing the result and verbal encouragement) led to significantly greater maximal voluntary isometric force compared to verbal encouragement itself or without stimulus, but there were no significant differences in the rate of force development among the conditions in this study. It appears that for students, verbal encouragement may have a significant role in a higher volume of strength training, but performance feedback stimulus could be more important for improving strength parameters.

Interesting findings from the 10 and $30 \mathrm{~m}$ sprint tests after comparing the results between verbal encouragement and attempts without stimuli showed that the change in the performance was not significant. This does not correspond with Edwards's study [48], which recorded significant improvement after applying verbal encouragement in cycling sprints $(2 \times 30 \mathrm{~s}$ Wingate) to recreationally active participants. It looks like VE has a more important role in sprint exercises with longer duration than sprints of short distance. Therefore, from the sprint results, it is obvious that verbal encouragement alone does not have any significant positive effect on students' performance. The great statistically significant change in time was achieved after applying VE + GO stimuli. This could have happened because of the realistic execution of this exercise in a competitive environment with a clear achievable aim (catching the rabbit). Verheijen [49], in his study on young football players, compared three different scenarios: $10 \mathrm{~m}$ non-competitive sprint test (only one player), two players at the same time and in a specific football competitive situation (one player with ball). The competitive group improved compared to the non-competitive group by about $2.5 \%$. The football specific group showed greater improvements $(6.5 \%)$ compared to the non-competitive group. Adopting an external focus of attention improved sprinting performance in low-skilled sprinters also in Porter's study [50]. From these results, it is clear that a competitive environment with goal-oriented stimulus or feedback that encourages performers to focus their attention externally could lead to a significant increase in performance.

The biggest statistical differences after applying external stimuli and without stimuli were seen in the vertical jump test. The verbal encouragement and combination stimuli led to greater improvements than without stimuli, and VE was not as effective as goal-oriented stimulus and VE together. The ball that students tried to reach was a strong motivation factor that helped them to better use their potential. A study with similar results was executed by Vasconcelos et al. [51], which was performed with U17 futsal players. The main findings of this study were that players achieved better results in the squat jump by about $9.2 \%$ and in countermovement jumps by about $4.8 \%$ after applying VE and a competitive motivational stimulus. Porter at al. [52] used stimulation when subjects were focusing on the target further from their body during a standing long jump and they achieved greater performance than the group without any external stimulation. Moreover, Keller et al. [53] found that augmented feedback (the jump performance was shown directly after the attempt) was even more effective than the vertical jump with the aim of touching a ball. This could mean that performance feedback could lead to even better results than the combination of VE and goal-oriented stimuli as it was in the exercise bench press.

The main finding of this study was that external stimuli or their combination led to increased performance compared to execution without external stimuli. Performance feedback was highly effective in the exercise bench press and verbal encouragement stimulus does not significantly improve performance in acceleration and speed tests. These short duration, explosive and intensive exercises are less sensitive to external stimuli (ceiling effect) for improvement compared to long duration exercises. Testing anaerobic abilities under these conditions could be beneficial for achieving more objective results from students. These external stimuli could be used not just in testing but also in training conditions in physical education environments [37]. Challenging, competitive and motivational environments during testing or exercising may also help to increase motivation, focus, effort and enjoyment during different exercises and tasks [54].

The main limitation of the study was that students always started testing without stimuli and they were not counterbalanced with external stimuli. It was noticed that 
some students' results could have been influenced by social environment, their daily tasks (homework, exams, hours of sleep), and mental and physical fatigue. The next factor was the environment during the testing where some students could have been strongly motivated or unmotivated by their peers. Furthermore, some students could have been surprised or scared by the verbal encouragement especially during the bench press test. Standard operating procedures for verbal encouragement were set up based on the words but not on the frequency or number of repetitions; on the other hand, this would be better suited to a real practical environment. In future studies, it would be interesting to separate GO stimulus from VE, which would show us the effect of each stimulus separately and not its combination, and apply performance feedback to the sprints and vertical jump test. It would also be interesting to see how these external stimuli would affect technical-skill tests in different sports.

\section{Conclusions}

These findings demonstrate the positive effects of external stimuli on the physical fitness of male university students compared to no stimuli during testing. However, each stimulus had a different effect on performance in the bench press, 10 and $30 \mathrm{~m}$ sprints and the vertical jump test. A combination of VE together with GO is the most effective at improving time in 10 and $30 \mathrm{~m}$ sprints and the height of the jump. In the bench press test, the highest result of mean power is achieved after performance feedback. VE stimulus is effective for improvement in the vertical jump test but is not effective in speed tests. All external stimuli (VE, PF, GO and CS) positively increase students' results during physical fitness testing and are a useful and effective tool for teachers during physical education classes.

\section{Practical Application}

It is important for teachers to recognize which external stimuli are effective during exercises and how individual students react to them. Thanks to this, it will be possible to use the correct methods of the respective stimuli to maximize students' performance during the class. Combination stimuli that are set up in a realistic, challenging and enjoyable scenario are appreciated by students and could lead to greater motivation and performance during physical activity. PF leads to an increase in performance during strength exercises, and VE is effective in particular exercises and also just with particular students. It is very important for the teacher to recognize in which scenarios and for which students this kind of stimulus should be applied. Generally, the combination of stimuli together might create a more suitable environment for students during physical education classes to achieve greater results in anaerobic physical fitness tests.

Author Contributions: Conceptualization, M.P.; methodology, M.P.; formal analysis, M.P.; investigation, M.P.; data curation, M.P.; writing—original draft preparation, M.P.; writing—review and editing, M.P., E.Z.; visualization, M.P.; supervision, E.Z.; project administration, M.P.; funding acquisition, M.P. All authors have read and agreed to the published version of the manuscript.

Funding: This work was supported by the Scientific Grant Agency of the Deanship of Scientific Research, King Fahd University of Petroleum and Minerals in Dhahran (SB181037), and the authors would like to recognize the efforts made by Prince Sultan University in funding the research with either fees, incentives, or seed grants.

Institutional Review Board Statement: The procedures followed the ethical standards on human experimentation stated in compliance with the 1964 Helsinki Declaration and its later amendments. The project was approved by the ethics committee of the Deanship of Scientific Research at King Fahd University of Petroleum and Minerals in Dhahran (SB181037; 14 February 2020).

Informed Consent Statement: Informed consent was obtained from all subjects involved in the study, and written informed consent has been obtained from the patients to publish this paper.

Data Availability Statement: The data presented in this study are available on request from the corresponding author. The data are not publicly available due to privacy reasons. 
Conflicts of Interest: The author declared no potential conflicts of interest with respect to the research, authorship, and/or publication of this article.

\section{References}

1. Ellliot, A.J.; Covington, M. Approach and Avoidance Motivation. Educ. Psychol. Rev. 2001, 13, 2.

2. Egli, T.; Bland, H.W.; Melton, B.F.; Czech, D.R. Influence of age, sex and race on college students' exercise motivation of physical activity. J. Am. Coll. Health 2011, 59, 399-406. [CrossRef] [PubMed]

3. Bekinari, A. Verbal Aggressiveness and Leadership Style of Sports Instructors and Their Relationship with Athletes' Intrisic Motivation. J. Creat. Educ. 2014, 5, 114-121. [CrossRef]

4. Bam, A. Psychological Aspects of Physical Education. 2016. Available online: https://www.slideshare.net/BamAmintao/ psychological-aspects-of-physical-education-65717489 (accessed on 11 November 2021).

5. Winnick, J.; Porretta, D. Adapted Physical Education and Sport, 6th ed.; Human Kinetics: Champaign, IL, USA, 2017.

6. Schunk, D.H. Self-efficacy, motivation, and performance. J. Appl. Sport Psychol. 1995, 7, 112-137. [CrossRef]

7. Reinboth, M.; Duda, J.L.; Ntoumanis, N. Dimensions of coaching behavior, need satisfaction, and the psychological and physical welfare of young athletes. Motiv. Emot. 2004, 28, 297-313. [CrossRef]

8. Nicaise, V.; Cogérino, G.; Bois, J.; Amorose, A. Students' perceptions of teacher feedback and physical competence in physical education classes: Gender effects. J. Teach. Phys. Educ. 2006, 25, 36-57. [CrossRef]

9. Badami, R.; VaezMousavi, M.; Wulf, G.; Namazizadeh, M. Feedback after good versus poor trials affects intrinsic motivation. Res. Q. Exerc. Sport 2011, 82, 360-364. [CrossRef]

10. Smither, J.W.; London, M.; Reilly, R.R. Does performance improve following multisource feedback? A theoretical model, meta-analysis, and review of empirical findings. Pers. Psychol. 2005, 59, 33-66. [CrossRef]

11. Strube, G.; Strand, B. Can Feedback Affect Motivation? Oahperd J. 2015, 52, 2015.

12. Coker, C.A. Motor Learning and Control for Practitioners with Online Labs, 3rd ed.; Holcomb Hathaway: Scottsdale, AZ, USA, 2013.

13. Koka, A.; Hein, V. Perceptions of teacher's feedback and learning environment as predictors of intrinsic motivation in physical education. Psychol. Sport Exerc. 2003, 4, 333-346. [CrossRef]

14. Amorose, A.J.; Horn, T.S. Intrinsic motivation: Relationships with collegiate athletes' gender, scholarship status, and perceptions of their coaches' behavior. J. Sport Exerc. Psychol. 2000, 22, 63-84. [CrossRef]

15. Chelladurai, P.; Saleh, S.D. Dimensions of leader behavior in sports: Development of a leadership scale. J. Sport Psychol. 1980, 2, 34-45. [CrossRef]

16. Halperin, I.; Pyne, D.B.; Martin, D.T. Threats to internal validity in exercise science: A review of overlooked confounding variables. Int. J. Sports Physiol. Perform. 2015, 10, 823-829. [CrossRef] [PubMed]

17. ATS Committee on Proficiency Standards for Clinical Pulmonary Function Laboratories. ATS statement: Guidelines for the six-minute walk test. Am. J. Respir. Crit. Care Med. 2002, 166, 111-117. [CrossRef]

18. American Thoracic Society. ATS/ACCP statement on cardiopulmonary exercise testing. Am. J. Respir. Crit. Care Med. 2003, 167, 211. [CrossRef]

19. Ferguson, B. ACSM's guidelines for exercise testing and prescription 9th Ed. 2014. J. Can. Chiropr. Assoc. 2014, $58,328$.

20. Guyatt, G.H.; Pugsley, S.O.; Sullivan, M.J.; Thompson, P.J.; Berman, L.; Jones, N.L.; Fallen, E.L.; Taylor, D.W. Effect of encouragement on walking test performance. Thorax 1984, 39, 818-822. [CrossRef]

21. Moffatt, R.J.; Chitwood, L.F.; Biggerstaff, K.D. The influence of verbal encouragement during assessment of maximal oxygen uptake. J. Sports Med. Phys. Fit. 1994, 34, 45-49.

22. Chitwood, L.F.; Moffatt, R.J.; Burke, K.; Luchino, P.; Jordan, J.C. Encouragement during maximal exercise testing of type A and type B scorers. Percept. Mot. Ski. 1997, 84, 507-512. [CrossRef]

23. Andreacci, J.L.; Lemura, L.M.; Cohen, S.L.; Urbansky, E.A.; Chelland, S.A.; Duvillard, S.P. The effects of frequency of encouragement on performance during maximal exercise testing. J. Sports Sci. 2002, 20, 345-352. [CrossRef]

24. Bullinger, D.L.; Hearon, C.M.; Gaines, S.A.; Daniel, M.L. Concurrent verbal encouragement and Wingate anaerobic cycle test performance in females: Athletes vs. non-athletes. Int. J. Exerc. Sci. 2012, 5, 239. [CrossRef] [PubMed]

25. Neto, J.M.; Silva, F.B.; De Oliveira, A.L.; Couto, N.L.; Dantas, E.H.; de Luca Nascimento, M.A. <b> Effects of verbal encouragement on performance of the multistage $20 \mathrm{~m}$ shuttle run. Acta Sci. Health Sci. 2015, 37, 25-30.

26. McCormick, A.; Meijen, C.; Marcora, S. Psychological determinants of whole-body endurance performance. Sports Med. 2015, 45, 997-1015. [CrossRef] [PubMed]

27. Midgley, A.W.; Marchant, D.C.; Levy, A.R. A call to action towards an evidence-based approach to using verbal encouragement during maximal exercise testing. Clin. Physiol. Funct. Imaging 2018, 38, 547-553. [CrossRef] [PubMed]

28. Engel, F.A.; Faude, O.; Kölling, S.; Kellmann, M.; Donath, L. Verbal encouragement and between-day reliability during highintensity functional strength and endurance performance testing. Front. Physiol. 2019, 10, 460. [CrossRef] [PubMed]

29. Hammami, R.; Nebigh, A.; Selmi, M.A.; Rebai, H.; Versic, S.; Drid, P.; Jezdimirovic, T.; Sekulic, D. Acute Effects of Verbal Encouragement and Listening to Preferred Music on Maximal Repeated Change-of-Direction Performance in Adolescent Elite Basketball Players-Preliminary Report. Appl. Sci. 2021, 11, 8625. [CrossRef]

30. Anzak, A.; Tan, H.; Pogosyan, A.; Brown, P. Doing better than your best: Loud auditory stimulation yields improvements in maximal voluntary force. Exp. Brain Res. 2011, 208, 237-243. [CrossRef] 
31. Belkhiria, C.; de Marco, G.; Driss, T. Effects of verbal encouragement on force and electromyographic activations during exercise. J. Sports Med. Phys. Fit. 2018, 58, 750-757. [CrossRef]

32. Lee, H.; Shin, J.; Kim, D.; Park, J. Effect of verbal encouragement on quadriceps and knee joint function during three sets of knee extension exercise. Isokinet. Exerc. Sci. 2021, 29, 155-162. [CrossRef]

33. McNair, P.J.; Depledge, J.; Brettkelly, M.; Stanley, S.N. Verbal encouragement: Effects on maximum effort voluntary muscle: Action. Br. J. Sports Med. 1996, 30, 243-245. [CrossRef]

34. Rheese, M.; Drinkwater, E.J.; Leung, H.; Andrushko, J.W.; Tober, J.; Hendy, A.M. The effects of verbal cueing for high intended movement velocity on power, neuromuscular activation, and performance. Scand. J. Med. Sci. Sports 2021, 31, 1115-1125. [CrossRef] [PubMed]

35. Miller, W.; Jeon, S.; Kang, M.; Song, J.S.; Ye, X. Does Performance-Related Information Augment the Maximal Isometric Force in the Elbow Flexors? Appl. Psychophysiol. Biofeedback 2021, 46, 91-101. [CrossRef]

36. Kraemer, W.J.; Fry, A.C.; Maud, P.; Foster, C. Physiological Assessment of Human Fitness. Strength Testing: Development and Evaluation Methodology; Maud, P., Foster, C., Eds.; Human Kinetics: Champaign, IL, USA, 1995; pp. 115-137.

37. Pacholek, M. The influence of various stimuli on motivation and physical fitness of physically active and non-active students. Ann. Appl. Sport Sci. 2021, 9, e954. [CrossRef]

38. Zemková, E. Stable to unstable differences in force-velocity-power profiling during chest presses and squats. J. Biomech. 2021, 122, 110463. [CrossRef] [PubMed]

39. Jennings, C.L.; Viljoen, W.; Durandt, J.; Lambert, M.I. The reliability of the FiTRO Dyne as a measure of muscle power. J. Strength Cond. Res. 2005, 19, 167-171.

40. Zemková, E.; Cepková, A.; Uvacek, M.; Šooš, L.U. A novel method for assessing muscle power during the standing cable wood chop exercise. J. Strength Cond. Res. 2017, 31, 2246-2254. [CrossRef] [PubMed]

41. Zemková, E.; Jelen, M.; Kováciková, Z.; Ollé, G.; Vilman, T.; Hamar, D. Power outputs in the concentric phase of resistance exercises performed in the interval mode on stable and unstable surfaces. J. Strength Cond. Res. 2012, 26, 3230-3236. [CrossRef]

42. Hamar, D. Výskokový ergometer-Princíp a možnosti uplatnenia v diagnostike trénovanosti a tréningovej praxi. In Príspevok z Pracovného Seminára Diagnostika a Rozvoj Odrazových Schopností; Tréningové Stredisko Salzburg-Riff: Hallein, Austria, 1991.

43. Tkáč, M.; Hamar, D.; Komadel, L.; Kuthanová, O. Measurement of anaerobic power of the lower limbs by the method of repeated jumps. Sports Train. Med. Rehab. 1990, 1, 317-325. [CrossRef]

44. Zemková, E.; Hamar, D. Jump Ergometer in Sport Performance Testing. Acta Univ. Palacki. Olomuc. Gymnica 2005, 35, 7-16.

45. Argus, C.K.; Gill, N.D.; Keogh, J.W.; Hopkins, W.G. Acute effects of verbal feedback on upper-body performance in elite athletes. J. Strength Cond. Res. 2011, 25, 3282-3287. [CrossRef]

46. Obmiñski, Z.; Mroczkowska, H. Verbal encouragement does not improve maximal isometric hand grip strength in male judokas. A short report. J. Combat. Sports Martial Arts 2015, 6, 63-66. [CrossRef]

47. Silva, S.B.; de Abreu, L.C.; Valenti, V.E.; Nogueira, D.V.; Moraes, É.R.; Natividade, V.; Gallo, P.R.; Herrero, D.; Zacaro, P.M.D. Verbal and visual stimulation effects on rectus femoris and biceps femoris muscles during isometric and concentric. Int. Arch. Med. 2013, 6, 38. [CrossRef] [PubMed]

48. Edwards, A.M.; Dutton-Challis, L.; Cottrell, D.; Guy, J.H.; Hettinga, F.J. Impact of active and passive social facilitation on self-paced endurance and sprint exercise: Encouragement augments performance and motivation to exercise. BMJ Open Sport Exerc. Med. 2018, 4, e000368. [CrossRef] [PubMed]

49. Verheijen, R. The Original Guide to Football Periodisation: Always Play with Your Strongest Team, Part 1; World Football Academy: Amsterdam, The Netherlands, 2016.

50. Porter, J.M.; Wu, W.F.; Crossley, R.M.; Knopp, S.W.; Campbell, O.C. Adopting an external focus of attention improves sprinting performance in low-skilled sprinters. J. Strength Cond. Res. 2015, 29, 947-953. [CrossRef] [PubMed]

51. Vasconcelos, A.B.; Farinon, R.L.; Perasol, D.M.; dos Santos, J.M.; de Freitas, V.H. Influência de estímulos motivacionais no desempenho em testes de salto vertical de atletas de futsal sub-17. Revista Brasileira de Educação Física e Esporte 2020, 34 , 727-733. [CrossRef]

52. Porter, J.M.; Anton, P.M.; Wu, W.F. Increasing the distance of an external focus of attention enhances standing long jump performance. J. Strength Cond. Res. 2012, 26, 2389-2393. [CrossRef] [PubMed]

53. Keller, M.; Lauber, B.; Gottschalk, M.; Taube, W. Enhanced jump performance when providing augmented feedback compared to an external or internal focus of attention. J. Sports Sci. 2015, 33, 1067-1075. [CrossRef]

54. Ekkekakis, P.; Parfitt, G.; Petruzzello, S.J. The pleasure and displeasure people feel when they exercise at different intensities: Decennial update and progress towards a tripartite rationale for exercise intensity prescription. Sports Med. 2011, 41, 641-671. [CrossRef] 